|| ISSN(online): 2589-8698 || ISSN(print): 2589-868X ||

International Journal of Medical and Biomedical Studies Available Online at www.ijmbs.info

NLM (National Library of Medicine ID: 101738825)

Index Copernicus Value 2020: 79.44

Original Research Article

Volume 6, Issue 01; January: 2022; Page No. 56-57

\title{
STUDY REGARDING ETHICAL VERSUS GENERIC PRESCRIPTION OF STATINS
}

\author{
Dr Shilpa Atwal ${ }^{1}$, Dr Jitender Thakur ${ }^{2}$ \\ ${ }^{1}$ Junior Resident, PGIMER, Chandigarh \\ ${ }^{2}$ Senior Resident, SLBS Medical College, Ner Chowk
}

Article Info: Received 03 December 2021; Accepted 02 January 2022

DOI: https://doi.org/10.32553/ijmbs.v6i1.2396

Corresponding author: Dr. Jitender Thakur

Conflict of interest: No conflict of interest.

\section{Abstract \\ Background: To study the ethical versus generic prescription of statins}

Methods: Study was conducted on Patients with indications for statins presenting to cardiology OPD,Medicine OPD and Endocrinology OPD and started on statins at PGIMER, Chandigarh, within a period of 9 months.

Results: In our study population, amongst the primary prevention group, a larger percentage about $56 \%$ were receiving generic prescription of statins and about $44 \%$ were receiving ethical prescription of statins. Whereas in secondary prevention group, about $45.5 \%$ of patients were receiving generic prescription and $54.5 \%$ were receiving ethical prescription .

Concluded: In our study population patients were equally prescribed on ethical $(49.8 \%)$ and generic prescriptions $(50.2 \%)$.

Keywords: Statin, Ethical, Generic

\section{Introduction}

The most clinicians and patients welcome decreased generic drug costs, it is essential that safety and effectiveness is not compromised. Although generic drugs have identical active ingredients as brand-name drugs, they are not exact replicas because their inactive ingredients (excipients) differ. Health Canada, like the US Food and Drug Administration (FDA), requires bioequivalence studies for generic drug approval. Bioequivalence studies typically enroll a small number of healthy volunteers (minimum, 12) who are usually given one dose of brandname and generic drug, and focus on drug absorption, only needing to show that a similar amount of the generic drug was absorbed at a similar rate as the brand-name drug. ${ }^{1-2}$

Statin efficacy was originally demonstrated with brandname statins versus placebo in large, secondary prevention trials with thousands of patients, reducing major coronary events by $27 \%$ to $44 \%$, mortality by $13 \%$ to $30 \%$, and coronary death by $18 \%$ to $42 \%$ in those with heart disease. Given that generic medications are approved on the basis of bioequivalence with brand-name medications in healthy volunteers, rather than the target population with or at risk of cardiovascular disease, there remains a substantial uncertainty regarding their clinical effectiveness and safety, as well as the mandatory substitution policies that ensue following their approval..$^{3-5}$

\section{Material and Methods}

\section{Study area:}

Patients with indications for statins presenting to cardiology OPD,Medicine OPD and Endocrinology OPD and started on statins at PGIMER, Chandigarh, within a period of 9 months.
Time period:

The study was conducted for 6 months in Cardiology OPD, Medicine OPD Endocrinology OPD and follow up was done for 3 months (from December 2018 to August 2019).

\section{Type of study:}

Descriptive cross-sectional for both primary and secondary objectives.

\section{Study population:}

Patients with indications for statins being prescribed statins at Cardiology, Medicine and Endocrinology OPD PGIMER, Chandigarh

\section{Study subjects and sample size:}

320 patients of both sexes and all ages with indications for statins being prescribed statins during the study period were chosen as cases.

Clinical records of all cases were reviewed for indications of statins andlipid profile was be done at baseline and after 3 months in all the subjects to study the response to statin therapy.

\section{Inclusion criteria:}

1. Patients with indications of statins for primary prevention according toAHA 2018 guidelineswho are not on statins or have been receiving statins for not more than one month.

2. Patients receiving statins for secondary prevention ofASCVD, who are not on statins or have been receiving statins for not more than one month. 


\section{Exclusion criteria:}

1. Patients with contraindications to statins (deranged LFTs: AST/ALT more than 5 times ULN).

2. Patients with ESRD/renal failure.

3. Patients who didn't give consent.

4. Patients lost to follow up.

5. Patients having mortality during the study period.

6. Patients who are already on statins for more than 1 month.

\section{Results}

In our study population,amongst the primary prevention group, a larger percentage about $56 \%$ were receiving generic prescription of statins and about $44 \%$ were receiving ethical prescription of statins. Whereas in secondary prevention group, about $45.5 \%$ of patients were receiving generic prescription and $54.5 \%$ were receiving ethical prescription. So in entire study population patients were equally prescribed on ethical $(49.8 \%)$ and generic prescriptions $(50.2 \%)$.

Table 1: Distribution of ethical versus generic drug prescriptions in study population

\begin{tabular}{|l|c|c|c|}
\hline \multirow{2}{*}{} & \multicolumn{2}{|l|}{ Prevention groups } & \multirow{2}{*}{ Total } \\
\cline { 2 - 4 } & $\begin{array}{c}\text { Primary } \\
\text { group }(\mathbf{n}=\mathbf{1 0 9})\end{array}$ & $\begin{array}{c}\text { Secondary group } \\
(\mathbf{n = 1 3 4})\end{array}$ & \\
\hline Ethical prescription & $48(44 \%)$ & $73(54.5 \%)$ & $121(49.8 \%)$ \\
\hline Generic prescription & $61(56 \%)$ & $61(45.5 \%)$ & $122(50.2 \%)$ \\
\hline
\end{tabular}

Data are presented as mean ( $95 \%$ confidence interval).

\section{Discussion}

In our study population, amongst the primary prevention group, a larger percentage about $56 \%$ was receiving generic prescription of statins and about $44 \%$ were receiving ethical prescription of statins. Whereas in secondary prevention group, about $45.5 \%$ of patients were receiving generic prescription and $54.5 \%$ were receiving ethical prescription. So there is almost equal proportion of generic and ethical prescriptions in OPD.Both the groups had a significant reduction in LDL and total cholesterol in our study. Our study results were similar to a study on prescription pattern of drugs in ischemic heart disease by Mahadeo $\mathrm{P}$ et $\mathrm{al}^{6}$ which showed that 1498 (29.99\%) drugs were prescribed by with generic names. In study by Nagabushan $\mathrm{H}_{\mathrm{et}} \mathrm{al}^{7}$, drugs prescribed by their generic names were $52.9 \%$ which is also similar to present study. Similar findings were reported in study Shankar R et al $(36.43 \%)^{8}$.

\section{Conclusion}

In our study population patients were equally prescribed on ethical and generic prescriptions.

\section{References}

1. IMS Institute for Healthcare Informatics. Medicines use and spending shifts. A review of the use of medicines in the U.S. in 2014. Parsippany, NJ: IMS Health; May 2015. Available at: http:// www.imshealth.com/en/thought-leader ship/ims-institute/reports/medicines-use-in-the-us2014.

2. IMS Brogan . Canadian pharmaceutical industry review 2012. Montreal: IMS Health; 2012.

3. Notice of compliance information. Health Canada; 2015. Available at: http://www.hc-sc.gc.ca/dhpmps/prodpharma/notices-avis/noc-acc/indexeng.php.

4. Ontario Ministry of Health and Long-Term Care. 2012/13 report card for the Ontario drug benefit program. 2013. Available at: http: //www.health. gov.on.ca/en/public/programs/drugs /publications/opdp/docs/odb_report 13.pdf.

5. Iosifescu A, Halm EA, McGinn $\mathrm{T}$, Siu AL, Federman AD. Beliefs about generic drugs among elderly adults in hospital-based primary care practices. Patient EducCouns. 2008;73:377-383

6. Sawant MP, Padwal SL, Jadhav RR, Pise HN, Shinde R. Study of drug prescription pattern in ischemic heart disease patients. International Journal of Basic \& Clinical Pharmacology. 2019 Jul;8(7):1473.

7. .Nagabushan H, Roopadevi HS, Prakash GM, Pankaja R. A prospective study of drug utilization pattern in cardiac intensive care unit at a tertiary care teaching hospital. Inter $\mathrm{J}$ BasiClinPharma. 2017;4(3):579-83.

8. Shankar R, Partha $P$, Shenoy N. Prescribing Patterns Of Drugs Among Patients Admitted With Cardiovascular Disorders In The Internal Medicine Ward.: Prescribing Patterns In Inpatients. The Internet Journal of Pharmacology. 2001;1:256-68. 